\title{
A breathing circuit disconnection detected by anesthetic agent monitoring
}

[Une déconnexion du circuit respiratoire détectée par le monitorage de l'anesthésique]

Robert Ross Kennedy PhD FAnZCA, Richard Anthony French FAnZCA

Purpose: To describe a case involving a spontaneously breathing patient where a circuit disconnection was detected by a change in monitored anesthetic agent parameters.

Clinical features: A patient undergoing shoulder surgery was breathing spontaneously from a circle type anesthesia circuit via a laryngeal mask. A disconnection occurred between the heat and moisture exchanger (HME) and the circle system's Y-piece. As the gas sampling port was integrated into the HME a near normal pattern of $\mathrm{CO}_{2}$ continued to be displayed. The disconnection was noted because of a change in the graphical display of the volatile agent concentration.

Conclusions: Anesthetic circuit disconnection can be difficult to detect, especially in the spontaneously breathing patient. Capnometry may not detect a disconnection on the machine side of the gas sampling port. Changes in oxygen and volatile agent concentrations may provide an early indication of these types of disconnection.

Objectif : Décrire un cas de déconnexion du circuit, impliquant un patient en respiration spontanée, détectée par un changement de paramètres des anesthésiques sous monitorage.

Éléments cliniques: On a utilisé, pour une intervention chirurgicale à l'épaule, une anesthésie en respiration spontanée avec masque laryngé et circuit cercle. Une déconnexion est survenue entre l'échangeur de chaleur et d'humidité (ECH) et la pièce en Y du circuit cercle. Comme le site d'échantillonnage du gaz est intégré à l'ECH, l'affichage quasi normal de $\mathrm{CO}_{2}$ s'est poursuivi. La déconnexion a été remarquée grâce à un changement dans le graphique de concentration de l'agent volatil.

Conclusion : Une déconnexion du circuit anesthésique peut être difficile à détecter, surtout si le patient respire spontanément. La capnométrie pourrait n'être d'aucun secours pour une déconnexion du côté de l'appareil où se trouve le site d'échantillonnage. Des changements de concentrations d'oxygène et d'anesthésique volatil peuvent alors fournir une indication précoce de ce type de déconnexion.

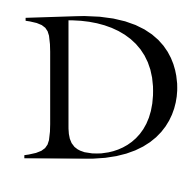

ISCONNECTIONS in the anesthetic breathing system are not uncommon. ${ }^{1,2}$ Some disconnections, such as those occurring at the common gas outlet, are notoriously difficult to detect, especially if the monitors continue to detect a near normal $\mathrm{CO}_{2}$ pattern. ${ }^{3}$ We describe an incident in which a disconnection was first detected by a change in the graphical representation of the concentration of the volatile anesthetic agent.

\section{Case report}

A 61-yr-old woman was undergoing shoulder stabilization. An interscalene block was performed, following which general anesthesia was induced using iv fentanyl and propofol. A size 3 reinforced laryngeal mask airway was inserted. The patient was breathing spontaneously via a circle circuit with fresh gas delivered at $1 \mathrm{~L} \cdot \mathrm{min}^{-1}$ and comprising sevoflurane $4 \%$ in air and oxygen. A Datex AS/3 (Datex/ Engstrom, Finland) anesthesia monitor was being used. Monitored variables were electrocardiography, non-invasive blood pressure, pulse oximetry, oxygen, carbon dioxide and anesthetic agent concentrations. The gas analysis sampling tube was connected to the gas sampling port of the heat and moisture exchanger (HME)/viral filter. The side-stream spirometry facility of the AS $/ 3$ monitor was also being used with the spirometer assembly being placed in the circuit between the HME and the Y-piece of the circuit.

At $30 \mathrm{~min}$ from commencement of the case, an abrupt fall in both the inspired and expired concentrations of sevoflurane was noted. It is our practice to display volatile anesthetic agent concentration as a "slow" waveform, thus one screen "sweep" represents a five minute trend. From this display it was immediately apparent that the agent concentration had fallen to about half its previous value (Figure 1). Further

From the Department of Anesthesia, Christchurch Hospital, Christchurch, New Zealand.

Address correspondence to: Dr. R.A. French, Department of Anesthesia, Christchurch Hospital, Riccarton Avenue, Christchurch, New Zealand. Phone: 03364 0288; Fax: 03364 0289; E-mail: anaesthesia@chmeds.ac.nz

Accepted for publication December 19, 2000.

Revision accepted April 18, 2001. 


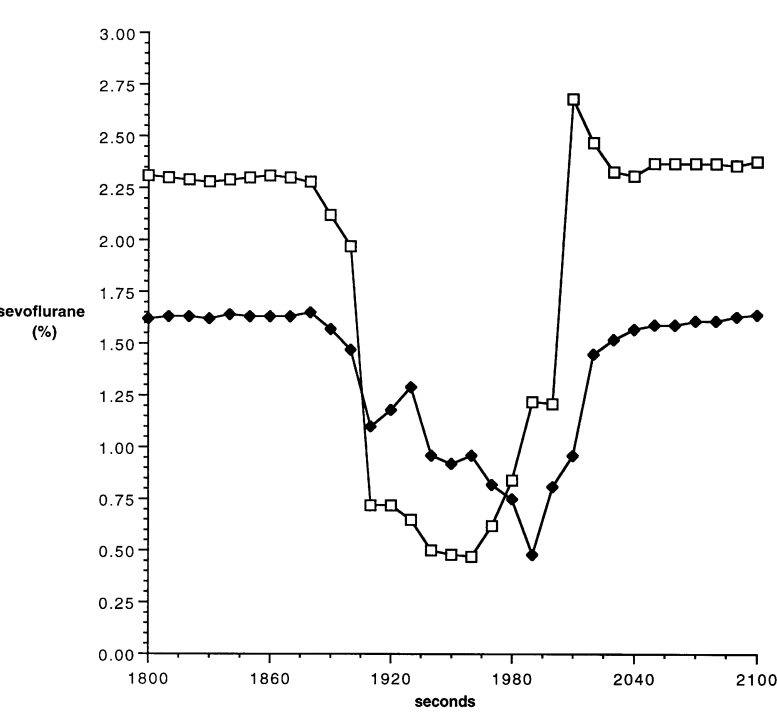

FIGURE 1 Plot of inspired (open symbols) and expired (closed symbols) sevoflurane concentrations during the disconnection.

The disconnection occurred $1875 \mathrm{sec}$ after commencement of the case. Data was reconstructed from that collected by a computer based data logging and trend display system in use in several of our theatres.

observation revealed that the circuit breathing gas reservoir had collapsed, the $\mathrm{FIO}_{2}$ had fallen to $23 \%$ and no tidal volume was being shown in the numeric display of spirometry data.

Inspection of the circuit showed a disconnection between the Y-piece/spirometer assembly and the HME/viral filter (Figure 2). This disconnection had been concealed beneath the surgical drapes and did not appear to have occurred in association with any movement of the patient by the surgeon. The circuit was reconnected, gas flows were increased and a few manual breaths were given to demonstrate circuit integrity. Anesthesia and surgery continued uneventfully. No alarms sounded during the disconnection.

\section{Discussion}

This incident combined two circumstances which can make circuit disconnections difficult to detect. The patient was breathing spontaneously and the disconnection occurred on the machine side of the gas sampling port. This incident has features in common with several types of disconnection, including those at the common gas outlet. Under these circumstances the patient is able to continue to breathe and room air is entrained into those components of the circuit still connected to the patient. Since the anesthetic gas mixture is progressively diluted by air, the main risks of

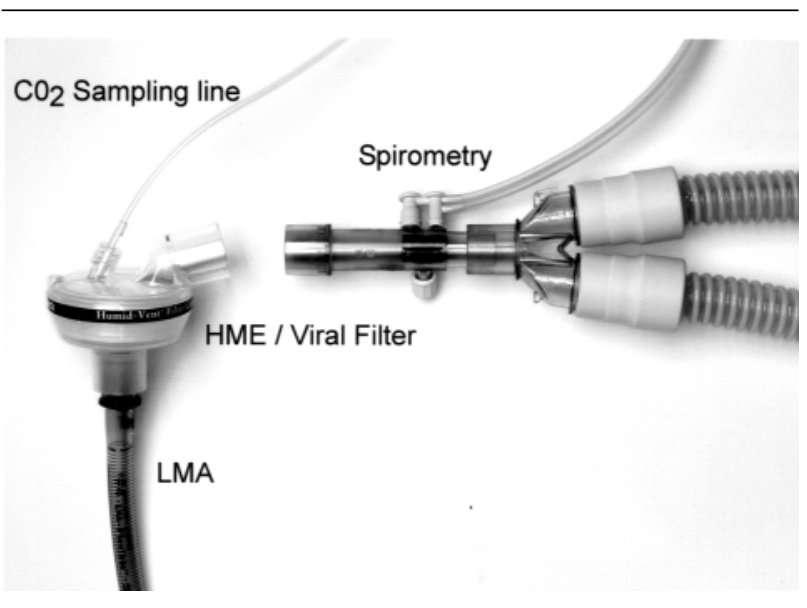

FIGURE 2 Circuit disconnection between laryngeal mask/heat and moisture exchanger (HME) and spirometer/Y-piece assemblies. The gas analysis sampling tube of the AS $/ 3$ anesthetic monitor is connected to the HME.

this type of disconnection are awareness and patient movement as the patient rouses rather than hypoxia. If this were to occur during precision procedures such as middle ear or opthalmic surgery adverse consequences for the patient might ensue.

In our case, several changes in measured gas concentrations occurred, all of which could be predicted. There was a marked fall in inspired and expired concentrations of the volatile anesthetic and $\mathrm{O}_{2}$, a rise in $\mathrm{FICO}_{2}$, and a fall in measured tidal volume (Figures $\mathrm{l}$ and 3 ). None of these changes triggered an alarm in the brief period of the incident. The change that alerted the anesthesiologist was the abrupt fall in sevoflurane concentration as shown on the monitor trace. The changes in inspired and expired sevoflurane followed a pattern similar to the changes in oxygen concentration. The fall in sevoflurane was more noticeable than the fall in $\mathrm{O}_{2}$ because it was a larger proportional change and also because it was being displayed as a"trend" graph, whereas the $\mathrm{O}_{2}$ concentrations were presented as numbers representing only instantaneous values. There is good evidence that a simple trend display, ${ }^{4}$ or more complex graphical displays ${ }^{5,6}$ aid in the detection of critical incidents. Alarm systems that integrate data from multiple variables may be better at detecting disconnections than alarms based on single parameters.

As is common practice, the alarm settings were the monitor defaults. ${ }^{8}$ The enabled monitors relating to ventilation were based on $\mathrm{CO}_{2}$ and $\mathrm{O}_{2}$. A breath is recognized when a rise in $\mathrm{CO}_{2}$ of greater than $8 \mathrm{mmHg}$ 


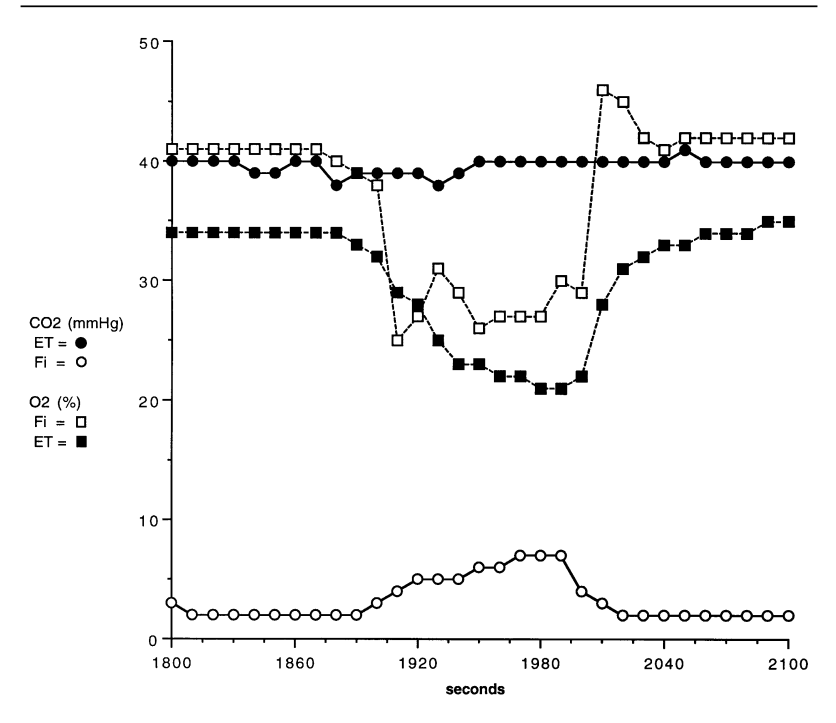

FIGURE 3 Plot of oxygen (squares) and $\mathrm{CO}_{2}$ (circles) concentrations during the disconnection. Open symbols are inspired concentrations and closed symbols are expired concentrations.

occurs and the "apnea" alarm sounds if no breath is detected for a period equivalent to five to seven breaths. The default alarm trigger points for oxygen are $18 \%$ for low $\mathrm{FIO}_{2}$ and $10 \%$ for low $\mathrm{ETO}_{2}$. Presuming that the entrained air has a normal $\mathrm{O}_{2}$ content, neither of these alarms would have sounded, regardless of the disconnection's duration. However, rebreathing of air trapped under the surgical drapes might have, eventually, led to a sufficient fall in $\mathrm{FIO}_{2}$ to trigger this alarm. Alarms based on tidal volume or low volatile anesthetic concentration were not enabled since these alarms require constant adjustment and are often perceived as a source of false alarms. Direct observation by the anesthesiologist detected this incident before any alarms. ${ }^{9}$ The setting of appropriate alarm values for each case is possible but may introduce new problems with errors in alarm value selection or alarm limit selection being so rigorous as to cause constant false alarms.

This disconnection occurred between two components of the circuit which are not normally assembled by the anesthesiologist. The fact that the disconnection occurred without an obvious precipitant suggests that the initial connection of these components may not have been "tight". This problem could possibly be avoided by designing a single piece circuit or using locking devices to secure the joints in a conventional circuit. Such devices have been described but can be bulky and do not fully eliminate the risk of disconnection. ${ }^{1}$

This case demonstrates a number of points.
Disconnections do occur, especially when surgery is near the head. Any joint in the circuit may be the point of disconnection and diligence should be applied to ensuring these are "tight", especially if they are concealed from the anesthesiologist's view. Capnometry may not detect disconnections on the machine side of the gas sampling port since the spontaneously breathing patient will continue to produce and expire $\mathrm{CO}_{2}$. Changes in oxygen and volatile agent concentrations may provide an early indication of some types of disconnection. Alarms based on multiple variables may detect disconnections in situations where multiple alarms each based on a single parameter do not. Finally, changes in data presented graphically may be more obvious than a change in data displayed only as the current numeric value.

\section{References}

1 Adams AP. Breathing system disconnections. Br J Anaesth 1994; 73: 46-54.

2 Russell WJ, Webb RK, Van Der Walt JH, Runciman WB. Problems with ventilation: an analysis of 2000 incident reports. Anaesth Intens Care 1993; 21: 617-20.

3 French $R A$, Kennedy $R R$. Disconnect alarm failure in detection of common gas outlet disconnection. Anaesth Intens Care 1998; 26: 665-70.

4 Murchie CJ, Kenny GN. Comparison among manual, computer-assisted and closed-loop control of blood pressure after cardiac surgery. J Cardiothoracic Anesth 1989; 3:16-9.

5 Michels P, Gravenstein D, Westenskow DR. An integrated graphic data display improves detection and identification of critical events during anesthesia. J Clin Monit 1997; 13: 249-59.

6 Blike GT, Surgenor SD, Whalen K. A graphical object display improves anesthesiologists' performance on a simulated diagnostic task. J Clin Monit Comput 1999 15: $37-44$.

$7 \mathrm{Orr}$ JA, Westenskow DR. A breathing circuit alarm system based on neural networks. J Clin Monit 1994; 10 101-9.

8 Block FE, Nuutinen L, Ballast B. Optimization of alarms: a study on alarm limits, alarm sounds, and false alarms, intended to reduce annoyance. J Clin Monit Comput 1999; 15: 75-83.

9 Gravenstein JS. Monitoring with our good senses (Editorial). J Clin Monit Comput 1998; 14: 451-3. 